Article

\title{
Potential Recovery of Biogas from Lime Waste after Juice Extraction Using Solid-Liquid Extraction Process
}

\author{
Oluwatosin J. Ogundare and David O. Olukanni *(D) \\ Department of Civil Engineering, Covenant University, PMB 1023, Canaan land, Ota 112233, Nigeria; \\ jacobtrice21@yahoo.com \\ * Correspondence: david.olukanni@covenantuniversity.edu.ng
}

Received: 28 April 2020; Accepted: 9 June 2020; Published: 19 June 2020

\begin{abstract}
A large percentage of fruit mass is left as waste after the consumption or processing of citrus fruits. The inappropriate disposal of these wastes directly leads to environmental and economic concerns. However, scientific investigations have demonstrated that citrus wastes, due to their high concentration in soluble sugars, can be a source of cellulosic biomass for biogas recovery. D-Limonene, the major constituent of essential oils present in citrus wastes, is however, known to hamper the conversion process of citrus wastes to biogas. With the aim of improving biogas production, a study on the pre-treatment of lime fruit waste to reduce the effect of $\mathrm{D}$-limonene was carried out. The pretreatment process was done using hexane as the solvent in a solid-liquid extraction process to leach out essential oils from lime wastes. Solid-liquid extraction was carried out in a Soxhlet apparatus with pulverized lime waste at $68{ }^{\circ} \mathrm{C}$ for $180 \mathrm{~min}$; then the residue was washed and aerated. From the pre-treatment procedure, $21.3 \mathrm{~mL}$ of essential oil was recovered, indicating an oil yield of $3.8 \%$. Substrates of untreated and pre-treated lime waste were digested in batches under mesophilic conditions for a period of 28 days. The biogas yield of each substrate was evaluated and the results compared. Substrate of untreated lime waste yielded $66.9 \mathrm{~mL} / \mathrm{g}$ VS. biogas after the digestion period. In comparison, pre-treated lime waste gave a better biogas yield of $93.2 \mathrm{~mL} / \mathrm{g}$ VS. after 28 days, indicating an improvement in biogas yield by about $40 \%$. The findings of this research show that there is a viable recovery option of biogas from lime waste, and recommendations of this research can be further explored to develop an economically viable biogas plant process that efficiently utilizes citrus wastes. This would boost the drive of government towards alternative sources of energy and also fulfil two of the sustainable development goals presented by the United Nations.
\end{abstract}

Keywords: waste management; environmental pollution; environmental sustainability; sustainable technology; lime wastes; D-limonene; biogas

\section{Introduction}

Citrus fruit crops are very valuable in the current global market [1]. The Food and Agriculture Organization (FAO) approximates citrus fruit production in the year 2016 to be about 125 million tonnes [2] (Figure 1). About $50 \%$ of the fruit mass is left as waste after fresh consumption or processing of citrus fruits [3]. Citrus wastes (CWs) typically signify an economic and environmental disposal problem. The build-up of citrus waste and other forms of municipal solid waste is an environmental nuisance, as such waste gives off an offensive stench, pollutes groundwater resources, and attracts disease vectors [4-8]. The potential resource from these wastes can be successfully harnessed by extracting valuable by-products from them [8]. Research efforts have helped develop the conversion of CWs into economically usable and valuable products, such as dried pulp for feeding animals, essential oils 
useful in aromatherapy, fragrances, cosmetics, nutritional supplements, domestic household products and pharmaceutical formulations, pectins and citric acid, and biogas generated from anaerobic digestion [4,9-15].

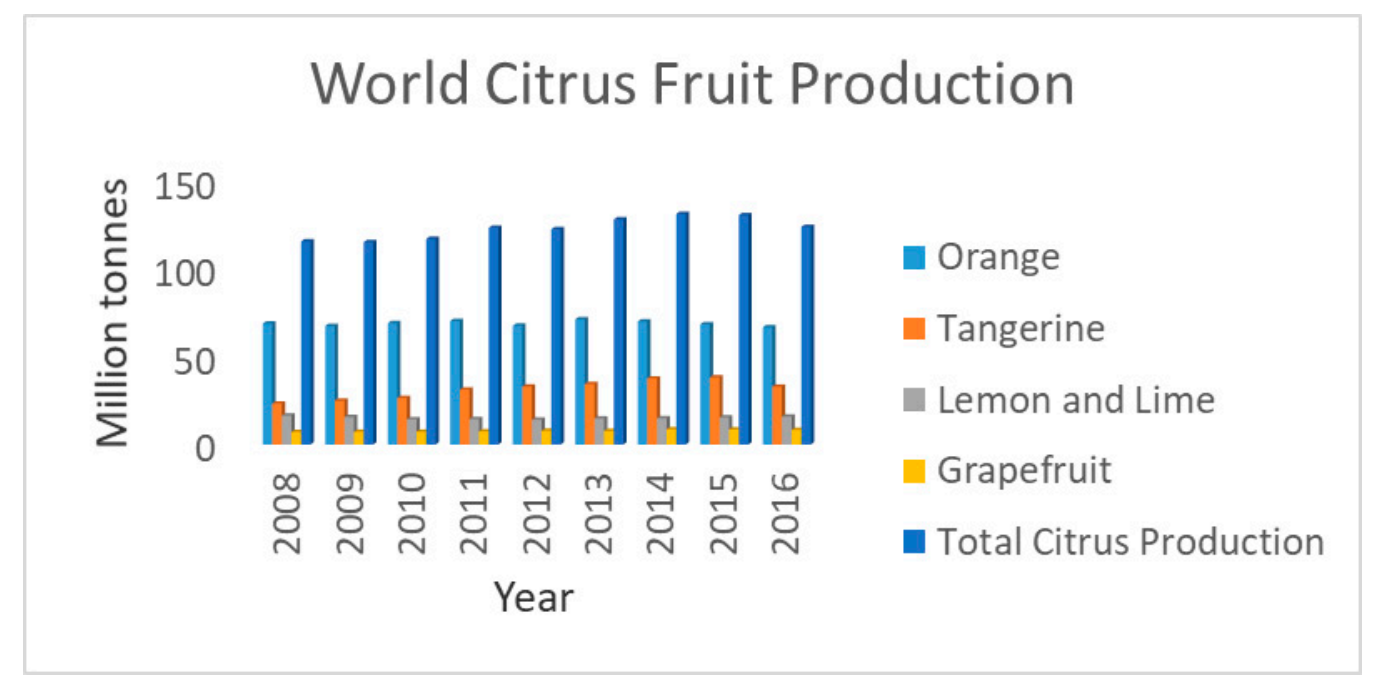

Figure 1. World citrus fruit production (FAO, 2018).

The chemical composition of CW consists of high concentrations of soluble sugars [3,16], making it a suitable source of cellulosic biomass for biofuel (bioethanol and biogas) generation $[17,18]$. Conversion of biomass to biogas is done through an anaerobic digestion process, under mesophilic or thermophilic conditions, which sustainably utilizes the potential of CWs [19]. Biogas serves as an alternative to fossil fuels and is useful for cooking, electricity, lightning, and vehicle fuel [17]. Anaerobic digestion of CWs to biogas therefore combines as a sustainable means to reduce environmental pollution's impact and produce clean energy [6,17]. However, the anaerobic conversion process of CW to biogas is hampered by the presence of D-limonene in citrus essential oils found in citrus peels $[19,20]$, consequently resulting in inefficiency in production processes and high production costs, thereby limiting the prospect of commercial production. D-Limonene is an anti-microbial agent that inhibits microbial actions and can cause total failure of anaerobic digestion systems [21-23]. According to Pourbafrani et al. [24], the threshold level of D-limonene for inhibiting anaerobic digestion under thermophilic conditions is between 450 and $900 \mu \mathrm{L} / \mathrm{L}$, while the threshold level under mesophilic conditions is $400 \mu \mathrm{L} / \mathrm{L}$ [25]. Researchers have overcome the effect of $\mathrm{D}$-limonene on anaerobic digestion by (i) the use of a cell protection system $[6,26,27]$, (ii) pre-treatment of CWs to reduce D-limonene concentration $[17,22]$, or (iii) co-digestion of $\mathrm{CW}$ with other waste materials of high organic content to reduce D-limonene concentration [23].

Several reported investigations have shown that different pre-treatment processes have successfully improved biogas yields from CWs. The pre-treatment of waste materials is usually achieved by physical, chemical, physicochemical, or biological methods including but not limited to milling, irradiation, microwave, steam explosion, ammonia fiber explosion (AFEX), supercritical $\mathrm{CO}_{2}$ and its explosion, alkaline hydrolysis, liquid hot-water pre-treatment, wet oxidation, ozonolysis, dilute-and concentrated-acid hydrolyses, and biological pre-treatments leading to an enhancement in the biodegradation of wastes for biogas production [28].

The most commonly reported pre-treatment process used in improving the biogas yields of CWs is steam explosion, which is known to have removed over $94 \%$ and $99 \%$ D-limonene and increased biogas yield up to $0.54 \mathrm{Nm}^{3} / \mathrm{kg}$ VS. [23] and $0.36 \mathrm{Nm}^{3} / \mathrm{kg} \mathrm{VS}$. [24], respectively. Additionally, Martin et al. [22], after pre-treating the orange peel waste with steam distillation, was able to remove $70 \%$ D-limonene content and reported methane yields of $0.23 \mathrm{~L} / \mathrm{g}$ VS. and $0.332 \mathrm{~L} / \mathrm{g}$ VS. under mesophilic and thermophilic conditions, respectively. Additionally, a number of pre-treatment processes have the 
extra advantage of essential oil recovery, which has proven useful in the pharmaceutical, cosmetic, food, and pest control industries [20]. A maximum oil yield of $1.34 \mathrm{~mL} / \mathrm{g}$ orange peel was recorded by Golmohammadi et al. [15] while Pourbafrani et al. [24] developed a process that could generate up to $8.9 \mathrm{~L} \mathrm{D}$-limonene from one ton of citrus waste using steam explosion. Nevertheless, these processes are performed under harsh conditions, requiring high energy use and can only be done using expensive equipment. A low energy demanding and less expensive pre-treatment alternative that is favorable for improving biogas yield is the solid-liquid extraction process. Previously, Giwa et al. [14] and Lopresto et al. [13] have recorded essential oil yields of $2.54 \%$ and $0.95 \%$, respectively using Soxhlet extraction. A study using this treatment process on orange peels, carried out by Wikandari et al. [29], indicated a methane yield of up to $0.217 \mathrm{~m}^{3} / \mathrm{kg} \mathrm{VS}$, although no attention was paid to the oil yield. This study examines essential oil and biogas potential recovery from lime wastes by reducing the effect of $\mathrm{D}$-limonene using solid-liquid extraction as a pre-treatment process.

\section{Results and Discussion}

\subsection{Pre-Treatment of Lime Waste and Essential Oil Recovery}

The solid-liquid extraction technique was employed to remove and recover essential oil, using a Soxhlet apparatus. Only one treatment method was examined due to financial constraints. The solidliquid extraction method was investigated due to its advantages of requiring less energy and less expensive equipment. The constraint also limited the investigation of several lime wastes to hexane ratios. Alternatively, only one lime waste to hexane ratio was examined and the best process parameters that gave the best oil yield in a previous study were adopted in this work. Although no separate analysis was done to determine the $\mathrm{D}$-limonene content in the lime waste before and after leaching, inferences can be drawn from the essential oil extraction, as D-limonene makes up a large proportion of it. Experimental runs were carried out in duplicates on ground lime waste under similar conditions. Results from the experiments indicated a $3.8 \%$ essential oil recovery, with $42.6 \mathrm{~mL}$ oil generated from $1 \mathrm{~kg}$ of lime waste. The $3.8 \%$ oil yield recorded in this work is higher than the value obtained in other works using a similar treatment method. Lopresto et al. [13] and Giwa et al. [14] recorded maximum yields of $0.95 \%$ and $2.54 \%$, respectively. The solid liquid ratio of 1:2.5 used in this work as compared to 1:25 employed by Lopresto et al. [13] is probable to have prompted a higher oil yield. On the other hand, the oil yield in this work was lower in value when compared to other treatment processes. Maximum oil yields of $4.40 \%$ and $3.47 \%$ were measured by Giwa et al. [14] in their use of steam distillation and water distillation treatment, respectively.

The extracted essential oil was further evaluated to have a density of $0.88 \mathrm{~g} / \mathrm{mL}$, and observed to have a dark orange color with a sweet and tangy scent; it was insoluble in water.

\subsection{Anaerobic Digestion}

The pHs, total solids, and volatile solid contents of the substrates used in this study are shown in Table 1. Of particular note is the reduction in $\mathrm{pH}$ values after the incubation period. This signifies the acidification of the anaerobic digestion process, causing the system to be unstable and limiting biogas production.

Table 1. $\mathrm{pH}$, total solids, and volatile solid contents of substrates and inoculum.

\begin{tabular}{cccc}
\hline & Blank & Untreated LWs & Treated LWs \\
\hline $\mathrm{pH}$ (initial) & 8.58 & 9.55 & 9.59 \\
$\mathrm{pH}$ (final) & 4.83 & 6.52 & 4.31 \\
$\mathrm{TS}(\%)$ & $10.0 \pm 0.7$ & $18.0 \pm 0.4$ & $7.0 \pm 0.6$ \\
VS (\% TS) & $81.0 \pm 5.4$ & $73.3 \pm 1.5$ & $77.0 \pm 7.1$ \\
\hline
\end{tabular}


The biogas recovery potentials of pre-treated and untreated lime wastes were evaluated under mesophilic conditions by batch anaerobic digestion. The experiments were incubated at room temperature without $\mathrm{pH}$ adjustments. The regulation of temperature for the anaerobic digestion process proved to be particularly challenging. All of the batch reactors would not fit into an incubator or a water bath due to the nature of the laboratory setup, especially the measurement system, and the temperature of the laboratory space used could not be regulated as there was no exclusive right to its use. The process had to be subjected to normal room temperature, although fluctuating, but within a range of $28.8-31.3^{\circ} \mathrm{C}$ over the digestion period. This falls within the mesophilic range. Biogas emission in all substrates was documented on a daily basis (Figure 2). In the untreated lime waste samples, biogas production was observed right from the first day of digestion at a magnitude of $0.6 \pm 0.5 \mathrm{~mL} / \mathrm{g}$ VS. In the following days, biogas production was observed to increase gradually, hitting a peak value of $12.6 \pm 1.8 \mathrm{~mL} / \mathrm{g}$ VS. on the seventh day. A steady decline in production followed and gas emission became significantly little after day thirteen, until the process came to a halt after the eighteenth day. However, most likely as a result of microbial regrowth in the anaerobic digestion system, minute production of biogas was detected towards the end of the digestion period. Similarly, to untreated lime waste samples, gas emission was also detected in pre-treated lime wastes right from the first day, although in smaller quantity. The subsequent days yielded significantly higher amounts of biogas. More than $60 \%$ of the total biogas generated over the incubation period was achieved between the second and fifth day with a maximum daily yield of $24.6 \pm 1.3 \mathrm{~mL} / \mathrm{g}$ VS. recorded on the third day of incubation. After the twelfth day, production became a little elevated until the end of the digestion period. Of particular note, biogas production peaked and began to dwindle early in pre-treated lime waste. This is reflected in its low $\mathrm{pH}$ value of 4.31 (Table 1), indicating that the anaerobic digestion process was affected by an early acidification of the system. The unavailability of a gas chromatograph equipment at the time of experimentation could not allow the investigation of biogas and essential oil composition.

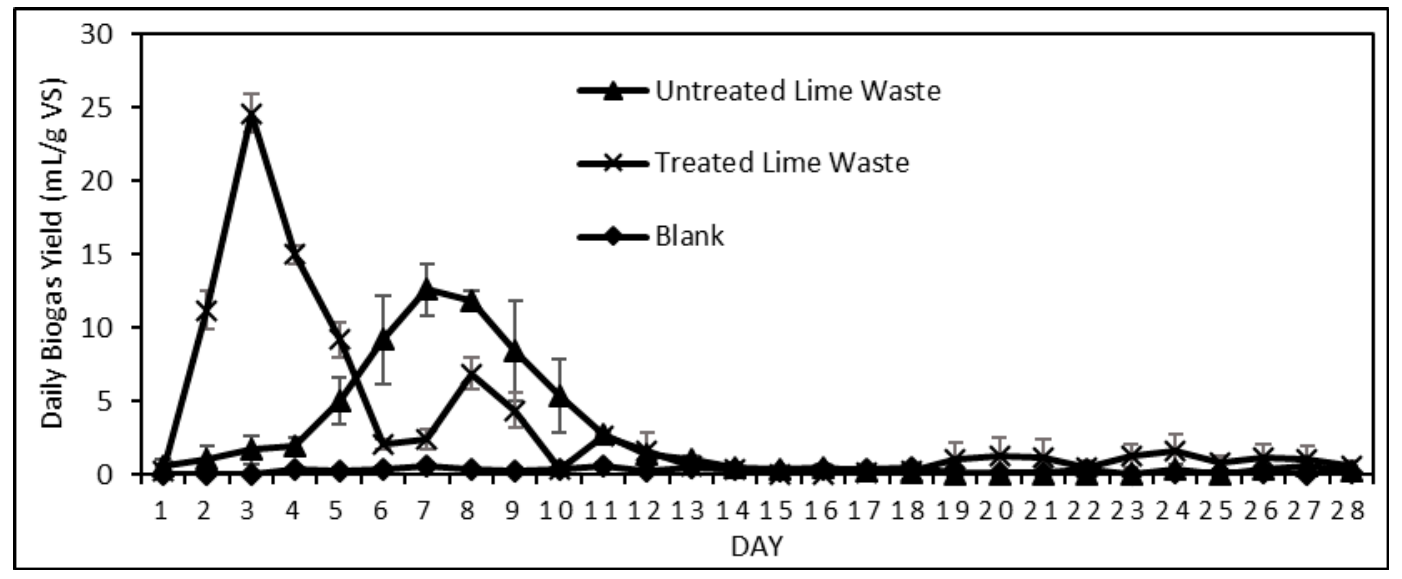

Figure 2. Daily biogas production of treated and untreated lime wastes.

The results of the cumulative biogas production (Figure 3) show that a higher volume of biogas was obtained in untreated lime waste $(946.9 \mathrm{~mL})$ when compared with pre-treated lime waste $(546.2 \mathrm{~mL})$. The higher amount of gas obtained in untreated lime waste can be attributed to more organic content for microorganisms to feed on due to its higher total solid content of $18 \%$ (Table 1). 


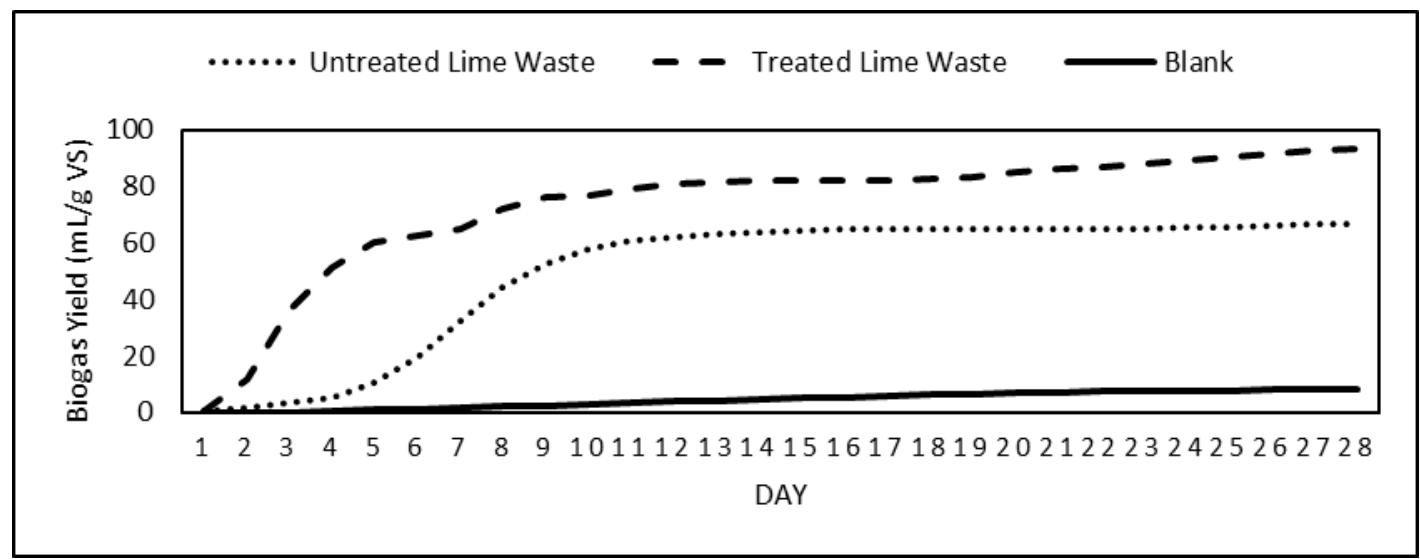

Figure 3. Cumulative biogas yield over the digestion period.

However, an accurate representation of how viable a substance is for biogas production is how much of its volatile solid content can be converted into biogas. From Figure 4, the volume of gas generated is expressed as a function of the volatile solid content used up and converted to biogas. It was evident that the treated lime waste was more viable for biogas generation $(93.2 \mathrm{~mL} / \mathrm{g} \mathrm{VS})$ than the untreated lime waste $(66.9 \mathrm{~mL} / \mathrm{g}$ VS). The pre-treatment process used in this work was able to improve biogas generation by about $40 \%$. In a similar study carried out previously by Wikandari et al. [29], with the same pre-treatment method of solid-liquid extraction, an over $300 \%$ increase in biogas yield was recorded. Wikandari et al. [28] measured an increment from $0.061 \mathrm{~m}^{3} / \mathrm{kg}$ VS. in untreated orange peel to a maximum biogas yield of $0.217 \mathrm{~m}^{3} / \mathrm{kg}$ VS. in treated orange peel. Similarly, Forgacs et al. [23] recorded an improvement of biogas yield from $0.102 \mathrm{~m}^{3} / \mathrm{kg}$ VS. in untreated citrus waste to $0.537 \mathrm{~m}^{3} / \mathrm{kg}$ VS. in citrus waste pre-treated by steam explosion, signifying an improvement in biogas yield by $426 \%$. While the biogas quantity $\left(0.067 \mathrm{~m}^{3} / \mathrm{kg}\right.$ VS) observed in untreated lime waste digested in this work can be corroborated with that observed in the work of Wikandari et al. [29] $\left(0.061 \mathrm{~m}^{3} / \mathrm{kg}\right.$ VS), it can be established that there was an inhibition in the biogas generation process for the treated lime waste, as is evident in its smaller yield of biogas as compared to the values obtained in the aforementioned literature. This inhibition can be attributed to the hexane residue present in pre-treated lime waste. Hexane has been established to have a negative impact on the anaerobic digestion process [29]. It is presumed that the solid-liquid ratio of 1:2.5 utilized during the pre-treatment phase led to high level of concentration of hexane in lime waste, consequently affecting biogas yield and causing an early failure of the anaerobic digestion system.

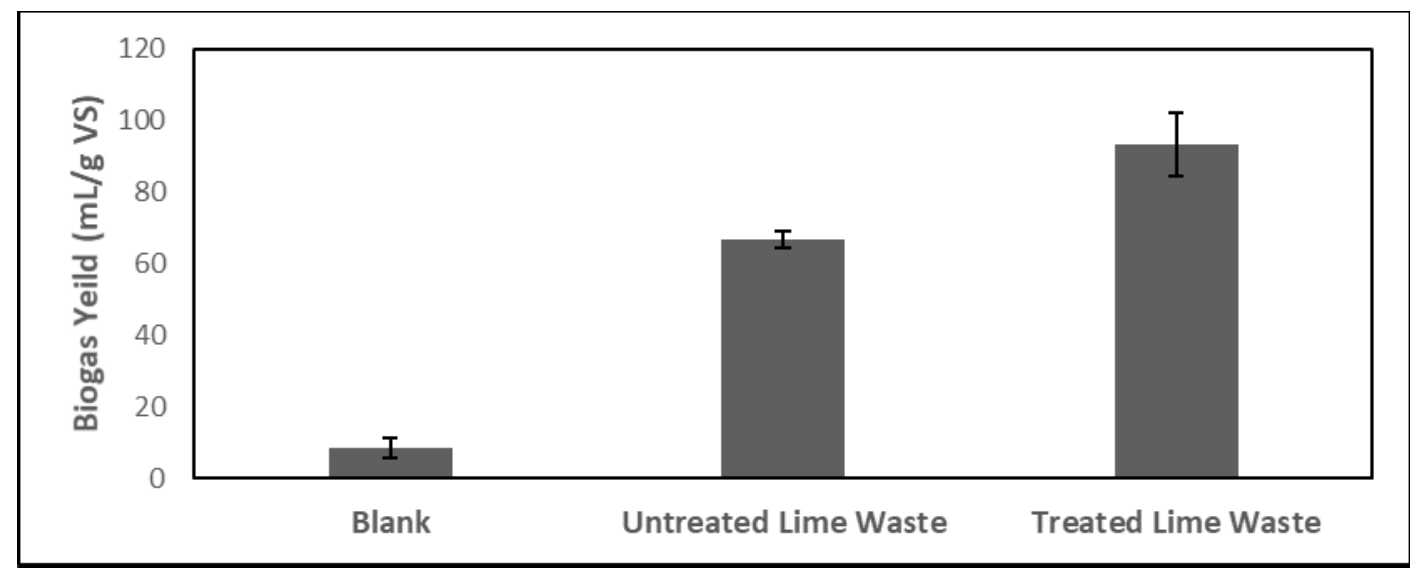

Figure 4. Total biogas production from anaerobic digestion of lime wastes. 


\section{Materials and Methods}

\subsection{Raw Material}

The citrus waste used in this work was mashed lime residue collected after the juice extraction process in a fruit juice processing company in Ota, Ogun State, Nigeria. The lime waste was collected and taken to the laboratory in a polythene bag. The collected material was transferred into clean, transparent plastic containers and stored in a refrigerator till it was needed.

\subsection{Pre-Treatment of Lime Waste and Recovery of Essential Oils}

Prior to the pre-treatment of lime waste, all of the lime waste sample collected was put in an oven at $35^{\circ} \mathrm{C}$ for $72 \mathrm{~h}$, as an alternative to sun-drying due to frequent rainfalls. This was done in order to remove moisture and ease pulverizing. After pulverization, the sample was divided into two equal halves. One-half of the pulverized sample, considered as the "untreated" portion of lime waste (untreated LW), was stored in a transparent plastic container, and kept in a refrigerator. The other half of pulverized lime waste was subjected to treatment by leaching out essential oils present in it through a solid-liquid extraction process. This experiment was performed in duplicate.

A Soxhlet apparatus was used to extract and recover essential oils as described by the Association of Official Analytical Chemists (AOAC) [30]. Hexane was used as solvent and added to the lime waste at a ratio of 2.5:1. Oil yield typically depends on extraction factors such as type of solvent, solid-to-solvent ratio, temperature, and extraction time. In this study, the extraction process occurred at a temperature of $68^{\circ} \mathrm{C}$ (hexane boiling point) over a duration of $180 \mathrm{~min}$, the extraction parameters that gave maximum oil yield as found in the work of Giwa et al. [14]. The extraction process occurred at a temperature of $68^{\circ} \mathrm{C}$ (hexane boiling point) over a duration of $180 \mathrm{~min}$, the extraction parameters that gave maximum oil yield as found in the work of Giwa et al. [14]. The extracted essential oil was cooled and stored in a plastic container. The treated LW was washed three times with distilled water and filtered. The filtered material was then left in open air for $48 \mathrm{~h}$ to allow excess hexane vaporization. The residue was considered as the "pre-treated" portion of lime waste (treated LW).

\subsection{Preparation of Substrate and Inoculum}

In this work, substrates (a) untreated lime wastes and (b) pre-treated lime wastes were considered. Substrate samples were prepared for digestion by mixing them with equal volumes of distilled water to form slurries. Fresh cow dung gotten from an abattoir in Ota, Ogun State, Nigeria was utilized as inoculum. The total solid (TS) content of substrates and inoculum was determined, measuring in triplicates, as described in the Method 1684 section of the United States Environmental Protection Agency (USEPA) [31].

\subsection{Batch Digestion Set-up}

The anaerobic digestion process was carried out in triplicate batch experiments. Air-tight Buchner flasks were improvised as bio-reactors. Figure 5 shows a typical batch setup: $200 \mathrm{~mL}$ of inoculum (cow dung) was first added to each flask, after which $100 \mathrm{~mL}$ of each substrate paste was added to designated flasks and labelled accordingly. The justification for the use of cow dung as inoculum was its local availability. If the biogas production process were to be adaptable to local industries, a readily-available source of inoculum would be cow dung. Blanks containing water to replace the substrate was used to determine the biogas production of the inoculum itself. Before the flasks were sealed, a $\mathrm{pH}$ meter was used to determine the $\mathrm{pH}$ value of substrate and inoculum mixture, as described in the standard method of American Public Health Association (APHA) [32]; pH values were equally measured after the incubation period. After $\mathrm{pH}$ measurements, the reactors were flushed with a gas containing $80 \% \mathrm{~N}_{2}$ and $20 \% \mathrm{CO}_{2}$ to ensure anaerobic conditions as described by Hansen et al., [33] and then sealed off using rubber corks. The outlets of the Buchner flasks were connected to the measuring system described in the following section. 


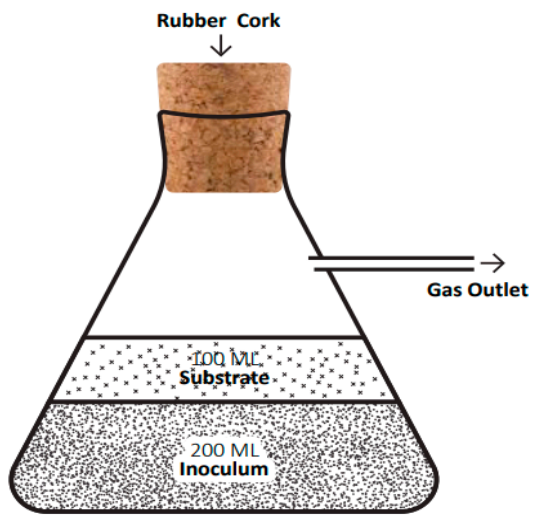

Figure 5. Bio-reactor.

The digestion (incubation) period was 28 days at room temperature. The absence of suitable equipment proved a barrier to maintaining a precise temperature during the testing period. However, the average daily temperature readings all through the 28-day digestion period were within mesophilic range $\left(25-45^{\circ} \mathrm{C}\right)$.

\subsection{Biogas Measurement}

During the laboratory batch digestion experiments, small amounts of gas were anticipated to be generated; therefore, a volumetric method of gas measurement was adopted. A liquid replacement system was developed as described by Pham et al., [34]. A liquid replacement system is an alternative with which to measure biogas generated from the substrates examined. The biogas was collected over distilled water as a substitute for alkaline solution as it is cheaper to obtain. While collection of biogas over an alkaline solution would have given a much more accurate representation of how much methane was generated, it was expected that collection over water would give a fair representation of the total amount of biogas generated to include methane and $\mathrm{CO}_{2}$, since they are insoluble and slightly soluble, respectively, in water, at room temperature. The outlet of the Buchner flask was connected-via a hose- to a capillary tube. The capillary tube was placed in a $1 \mathrm{~L}$ beaker filled with distilled water and positioned at the opening of an inverted $50 \mathrm{~mL}$ burette filled with distilled water (Figure 6). Gas was collected into the inverted, water filled burette via the capillary tube, and as gas was being generated, water was displaced and gas bubbles moved up to occupy the volume of space vacated. The volume of water displaced is equivalent to the volume of gas generated. Owing to the limited volume of the burette $(50 \mathrm{~mL})$, there was a frequent need to fill water back to the $50 \mathrm{~mL}$ mark on the burette.

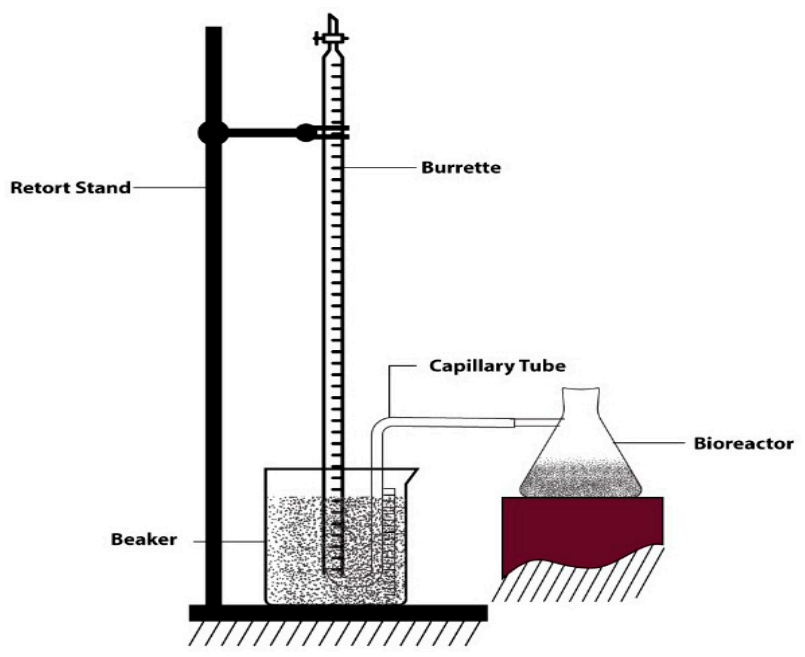

Figure 6. Laboratory setup to collect and measure biogas. 
Taking into account the limitations and resulting variation in the experimental method used in this study, the steps involved right from the collection of lime waste up till the production of biogas are displayed in a block flow diagram, as shown in Figure 7.

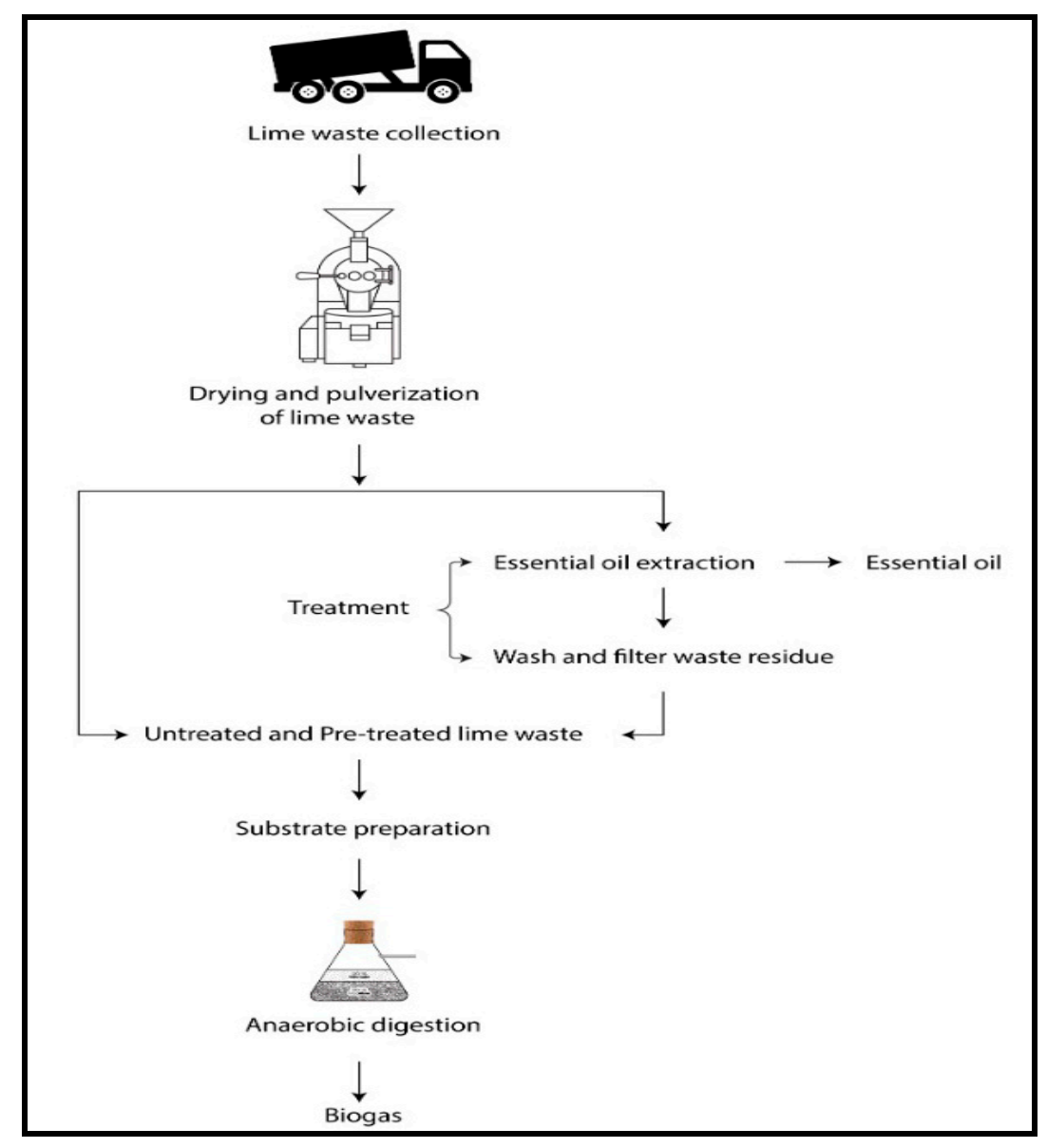

Figure 7. Flow diagram of experimental procedure.

\section{Conclusions and Recommendation}

In this study, potential biogas recovery from lime waste was examined. Since existing literature established the inhibitory effect of D-limonene present in citrus peels on anaerobic digestion, this work examined the pre-treatment of lime waste to reduce the effect of D-limonene and consequently improve biogas yield. The following conclusions were drawn from this study:

i. The pre-treatment of lime wastes using a solid-liquid extraction procedure led to an essential oil yield of $3.8 \%$. Essential oil is a high value product that is extensively useful in aromatherapy, fragrances, cosmetics, nutritional supplements, domestic household products, and pharmaceutical formulations.

ii. The amounts of biogas produced by untreated and pre-treated lime wastes over a 28-day incubation period are $66.9 \mathrm{~mL} / \mathrm{g}$ VS. and $93.2 \mathrm{~mL} / \mathrm{g}$ VS, respectively.

iii. The pre-treatment technique was able to reduce D-limonene's effect on the anaerobic process, as evidenced in improved biogas production from pre-treated lime waste. However, it is suggested that residual chemicals from the pre-treatment process might have hindered biogas production, causing just about $40 \%$ improvement in biogas yield.

Although several limitations were experienced in the course of this research, it was found that the methodology adopted in this work could prove to be a method for future studies to be carried out 
by those facing similar challenges. However, the results of the anaerobic digestion process should be taken with caution. The innovative idea of this research was to conduct investigation in developing a locally adaptable and conservative citrus waste management technique. This pilot study has been carried out with available resources and easily obtainable local materials as an alternative to more sophisticated apparatus. The findings of this research show that there is a viable recovery option of biogas from lime waste. This should boost the drive of government towards alternative sources of energy and also fulfil two of the sustainable development goals presented by the United Nations.

Author Contributions: Conceptualization of the research work came from D.O.O. and the methodology adopted was carried out by the authors D.O.O. and O.J.O. All the authors played roles in the use of the software, and the validation of the work was carefully checked by D.O.O. The formal analysis and investigation was done by D.O.O. and O.J.O. Resources and data curation were carried out by D.O.O. and O.J.O. The writing of the original draft was done by D.O.O. and O.J.O. Writing - review editing, D.O.O. Visualization, supervision and project administration were done by D.O.O. All authors have read and agreed to the published version of the manuscript.

Funding: This research received no external funding.

Acknowledgments: The authors appreciate the management of Covenant University for their providing of an environment that enabled us to carry out this research. We also appreciate the various authors of resource materials that were used which provided relevant information that led to the success of this work. The authors also appreciate the management of Juice company for calling the attention of the principal investigator (PI) to solving the problem of their waste and also for access to the collection of waste samples. A special thanks to O.O. Ajani, HOD Chemistry, Covenant University for providing access to the Chemistry laboratory, and Durodola of the Chemistry Department for his support in the course of this project. The Department of Civil Engineering is also appreciated for providing access to the available laboratory equipment/facility for the experiments.

Conflicts of Interest: The authors declare no conflict of interest.

\section{References}

1. Olife, I.C.; Ibeagha, O.A.; Onwualu, A.P. Citrus Fruits Value Chain Development in Nigeria. J. Biol. Agric. Healthc. 2015, 5, 36-47.

2. Food and Agriculture Organization. Orange Production in Year 2016. Available online: http://www.fao.org/ docrep/006/y5143e/y5143e12.htm (accessed on 3 December 2018).

3. Marın, R.F.; Cristina, S.; Obdulio, B.; Julian, C.; Jose, A.P. By-products from different Citrus Processes as a Source of Customized Functional Fibres. J. Food Chem. 2007, 100, 736-741. [CrossRef]

4. Owens, S.H.; Veldhuis, M.K.; Maclay, W.D. Making Use of Tons of Citrus Waste. In 1950-1951 Yearbook of Agriculture; 268-27. Available online: https://naldc.nal.usda.gov/download/IND43894068/PDF (accessed on 14 February 2020).

5. Olukanni, D.O.; Pius-Imue, F.B.; Joseph, S.O. Public Perception of Solid Waste Management Practices in Nigeria: Ogun State Experience. Recycling 2020, 5, 8. [CrossRef]

6. Olukanni, D.O.; Akinyinka, O.O.; Ede, A.N.; Akinwumi, I.I.; Ajanaku, K.O. Appraisal of municipal solid waste management, its effect and resource potential in a semi-urban city. J. South Afr. Bus. Res. 2014, 2014, 1-13. [CrossRef]

7. Wikandari, R.; Youngsukkasem, S.; Millati, R.; Taherzadeh, M.J. Performance of semi-continuous membrane bioreactor in biogas production from toxic feedstock containing D-Limonene. Bioresour. Technol. 2014, 170, 350-355. [CrossRef] [PubMed]

8. Olukanni, D.O.; Aipoh, O.A.; Kalabo, I.H. Recycling and reuse technology: Waste to wealth initiative in a private tertiary institution, Nigeria. Recycling 2018, 3, 44. [CrossRef]

9. Burt, S. Essential oils: Their antibacterial properties and potential applications in foods-A review. Int. J. Food Microbiol. 2004, 94, 223-253. [CrossRef]

10. Fisher, K.; Phillips, C. Potential antimicrobial uses of essential oils in food: Is citrus the answer? Trends Food Sci. Technol. 2008, 19, 156-164. [CrossRef]

11. Viuda, M.M.; Ruiz, N.Y.; Fernandez, L.J.; Perez, A.J. Antibacterial activity of lemon (Citrus lemon L.), mandarin (Citrus reticulata L.), grapefruit (Citrus paradisi L.), and orange (Citrus sinensis L.) essential oils. J. Food Control 2008, 19, 1130-1138. [CrossRef]

12. Ong, H.F. Extraction of Essential Oil from Orange Peels. Bachelor of Science's Thesis, University of Malaysia, Pahang, Malaysia, 2012. 
13. Lopresto, C.G.; Petrillo, F.; Casazza, A.A.; Aliakbarian, B.; Perego, P.; Calabro, V. A non-conventional method to extract d-Limonene from waste lemon peels and comparison with traditional Soxhlet extraction. Sep. Purif. Technol. 2014, 137, 13-20. [CrossRef]

14. Giwa, S.O.; Muhammad, M.; Giwa, A. Utilizing orange peels for essential oil production. ARPN J. Eng. Appl. Sci. 2018, 13, 17-27.

15. Golmohammadi, M.; Borghei, A.; Zenouzi, A.; Ashrafi, N.; Taherzadeh, M.J. Optimization of essential oil extraction from orange peels using steam explosion. Heliyon 2018, 4, e00893. [CrossRef]

16. Rivas-Cantu, R.C.; Jones, K.D.; Mills, P.L. A citrus waste-based bio-refinery as a source of renewable energy: Technical advances and analysis of engineering challenges. J. Waste Manag. Res. 2013, 31, 413-420. [CrossRef] [PubMed]

17. Forgacs, G. Biogas Production from Citrus Wastes and Chicken Feather: Pre-Treatment and Co-Digestion. Doctoral dissertation, Chalmers University of Technology, Göteborg, Sweden, 2012.

18. Olukanni, D.O.; Olatunji, T.O. Cassava waste management and biogas generation potential in selected local government areas in Ogun State, Nigeria. Recycling 2018, 3, 58. [CrossRef]

19. Zema, A.D.; Adele, F.; Giovanni, Z.; Calabro, P.S.; Tamburino, V.; Santo, M.Z. Anaerobic digestion of orange peel in a semi-continuous pilot plant: An environmentally sound way of citrus waste management in agro-ecosystems. Sci. Total Environ. 2018, 630, 401-409. [CrossRef] [PubMed]

20. Martin, M.A.; Fernandez, R.; Gutierrez, M.C.; Siles, J.A. Thermophilic anaerobic digestion of pre-treated orange peel: Modelling of methane production. J. Process Saf. Environ. Prot. 2018, 117, 245-253. [CrossRef]

21. Lohrasbi, M.; Pourbafrani, M.; Niklasson, C.; Taherzadeh, M.J. Process design and economic analysis of a citrus waste biorefinery with biofuels and limonene as products. Bioresour. Technol. 2010, 101, 7382-7388. [CrossRef] [PubMed]

22. Martın, M.A.; Siles, J.A.; Chica, A.F.; Martın, A. Biomethanization of orange peel waste. Bioresour. Technol. 2010, 101, 8993-8999. [CrossRef]

23. Forgacs, G.; Pourbafrani, M.; Niklasson, C.; Taherzadeh, M.J.; Hovath, I.S. Methane production from citrus wastes: Process development and cost estimation. J. Chem. Technol. Biotechnol. 2012, 87, 250-255. [CrossRef]

24. Pourbafrani, M.; Forgacs, G.; Sarvari, H.I.; Niklasson, C.; Taherzadeh, M.J. Production of biofuels, limonene and pectin from citrus wastes. J. Bio-Resour. Technol. 2010, 101, 4246-4250. [CrossRef]

25. Mizuki, E.; Akao, T.; Saruwatari, T. Inhibitory effect of citrus Unshu peel on anaerobic digestion. Biol. Wastes 1990, 33, 161-168. [CrossRef]

26. Pourbafrani, M.; Talebnia, F.; Niklasson, C.; Taherzadeh, M.J. Protective effect of encapsulation in fermentation of limonene-contained media and orange peel hydrolyzate. Int. J. Mol. Sci. 2007, 8, 777-787. [CrossRef]

27. Wikandari, R.; Millati, R.; Muhammad, N.C.; Taherzadeh, M.J. Biogas production from citrus waste by membrane bioreactor. Membranes 2014, 4, 596-607. [CrossRef] [PubMed]

28. Taherzadeh, M.J.; Karimi, K. Pre-treatment of lignocellulosic waste to improve ethanol and biogas production: A review. Int. J. Mol. Sci. 2008, 9, 1621-1651. [CrossRef]

29. Wikandari, R.; Niklasson, C.; Nguyen, H.; Millati, R.; Taherzadeh, M.J. Improvement of biogas production from orange peel waste by leaching of limonene. BioMed Res. Int. 2014, 2015, 1-6. [CrossRef]

30. Helvich, K. Official Method of Analysis, 13rd ed.; Association of Official Analytical Chemists: Washington, DC, USA, 2000.

31. United States Environmental Protection Agency. Total, Fixed, and Volatile Solids in Water, Solids, and Biosolids; Environmental Protection Agency Office of Water: Washington, DC, USA, 2001.

32. American Public Health Association. Standard Methods for the Examination of Water and Wastewater, 21st ed.; U.S. Environmental Protection Agency Office of Water: Washington, DC, USA, 2005.

33. Hansen, T.L.; Schmidt, J.E.; Angelidaki, I.; Marca, E.; Jansen, J.; Mosbæk, H.; Christensen, T.H. Method for determination of methane potentials of solid organic waste. Waste Manag. 2004, 24, 393-400. [CrossRef]

34. Pham, C.H.; Triolo, J.M.; Cu, T.T.T.; Pedersen, L.; Sommer, S.G. Validation and recommendation of methods to measure biogas production potential of animal manure. Asian Australas. J. Anim. Sci. 2013, 26, 864-873. [CrossRef]

(C) 2020 by the authors. Licensee MDPI, Basel, Switzerland. This article is an open access article distributed under the terms and conditions of the Creative Commons Attribution (CC BY) license (http://creativecommons.org/licenses/by/4.0/). 